\title{
Acute osteomyelitis in Nigerians with sickle cell disease
}

\author{
WALTON W EBONG \\ From the University College Hospital, Ibadan, Nigeria
}

SUMMARY Acute osteomyelitis comprised 78(29.3\%) of the 266 major skeletal complications seen in 207 patients with sickle cell disease in a five and a half year period. Forty eight $(61.5 \%)$ of the 78 patients were under the age of 15 years, and the mean age at onset was 12 years (range 9 months to 50 years). Osteomyelitis was often multifocal (in $42 \%$ of the cases) and associated with some life threatening disorders. Salmonella accounted for $50 \%$ of the 36 organisms isolated from 32 patients with bacteriologically confirmed diagnosis. The 'best guess' antibiotic was a combination of chloramphenicol and cloxacillin. Medical treatment alone proved adequate in most cases. No deaths resulted, but $55 \%$ of the patients developed serious complications due partly to the severity of the disease and also to infection involving the epiphyses and joints.

Key words: anaemia (sickle cell), haemoglobin sickle cell disease, Africa (western, Nigeria).

Although acute osteomyelitis is probably the most commonly reported major skeletal complication of sickle cell disease, detailed study of this complication has come mainly from the developed, nonmalarial countries (where both sickle cell disease and osteomyelitis are uncommon ${ }^{1}$ ); few similar studies have emanated from tropical Africa where sickle cell is very common and skeletal infection rampant. ${ }^{2} 3$ Previous studies from tropical Africa were either limited to Salmonella osteomyelitis, ${ }^{4} 5$ or they were based on rather few patients. ${ }^{3} 6-9$

This paper reviews the pattern of acute osteomyelitis in 78 consecutive patients with sickle cell disease seen at the University College Hospital (UCH), Ibadan, in a five and a half year period, and compares it with previous reports from tropical Africa and elsewhere.

\section{Patients and methods}

Between June 1976 and December 1981 the author studied prospectively 207 consecutive Nigerians with sickle cell disease and 266 major skeletal complications at the UCH, Ibadan. The major skeletal complications encountered were: osteomyelitis, 129

Accepted for publication 28 April 1986.

Correspondence to Dr Walton W Ebong, Orthopaedic Unit, Department of Surgery, University College Hospital, Ibadan, Nigeria.
(48.5\%); aseptic necrosis of the femoral head, 75 (28.2\%); septic arthritis, $31(11.7 \%)$; pathological fracture, $26(9.8 \%)$; and miscellaneous complications, five $(1.9 \%)$. Of the 129 patients with pyogenic infection of bone, 75 had acute osteomyelitis; 51 chronic osteomyelitis, and three had both acute and chronic osteomyelitis of different bones. Thus there were 78 cases of acute osteomyelitis, and the present account concerns only these cases.

The initial diagnosis of acute osteomyelitis was clinical, based on history of pains and swelling of the affected part(s), fever, malaise, and inability to use the affected part(s), and on objective signs of pyrexia, localised bone tenderness, and clinical findings suggestive of septicaemia. In most cases the diagnosis was quite obvious and difficulties in distinguishing the disease from bone infarction were infrequent because most of the patients presented late with florid disease.

In 32 patients $(41 \%)$ the clinical diagnosis of osteomyelitis was supported by a positive blood or pus culture, or both. Twelve patients with negative cultures but with clinical and radiological features consistent with osteomyelitis were presumed to have this disease and were included in the series. No cultures were taken from the remaining 34 cases because of lack of facilities at that time, but these cases were included in the series because they were obviously septic with either discharging sinuses, pus 


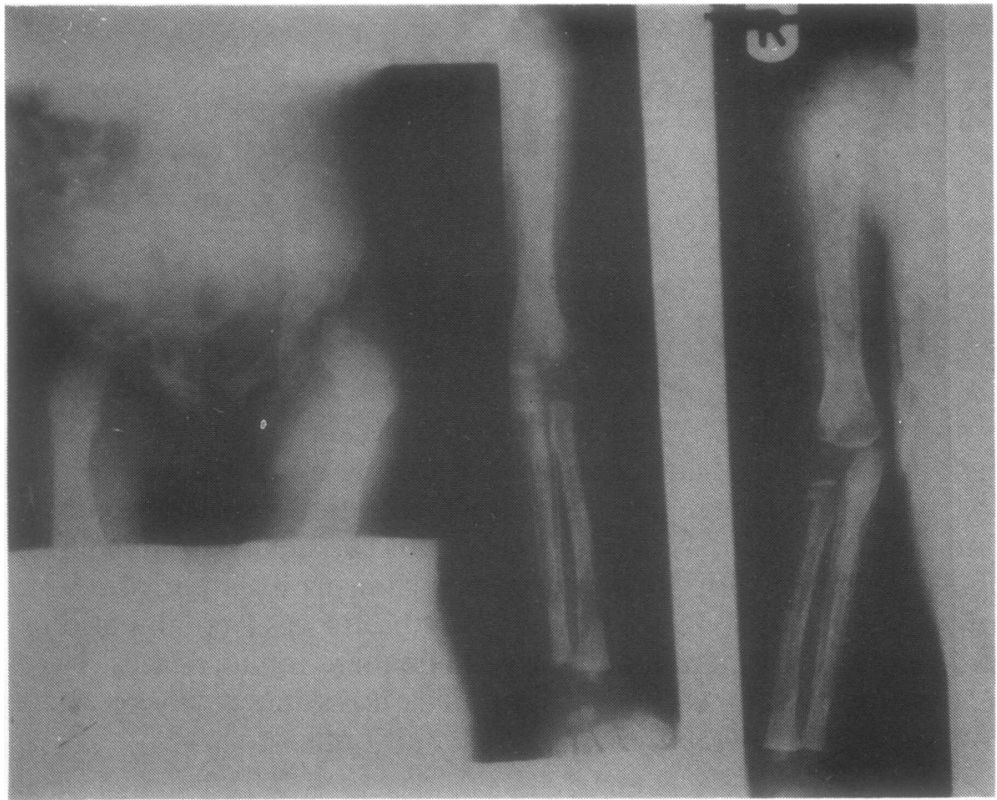

Fig. $1 \quad x$ Rays showing bilateral symmetrical Salmonella osteomyelitis of both iliac bones, humerus, radius, and ulna in a boy with sickle cell anaemia aged 1.5 years.

and/or persistent toxicity (in the absence of malaria) in the presence of radiological bone changes.

In every case the diagnosis of sickle cell disease was confirmed by haemoglobin electrophoresis and, where possible, by family studies and by estimation of fetal haemoglobin and haemoglobin $\mathrm{A}_{2}$ levels.

\section{STATISTICAL METHOD}

Student's $t$ test was used to compare means, and the $\chi^{2}$ test was used to detect association between important characteristics.

\section{Results}

AGE, SEX, AND HAEMOGLOBIN TYPE

The age at onset of osteomyelitis was between 9 months and 50 years (mean 12 years). The mean age for male patients (mean 10 years $3 \frac{1}{2}$ months; range 9 months to 23 years) was significantly less than that for female patients (mean 141/2 years; range 2 to 50 years) $(p<0 \cdot 01)$. The highest incidence (39 cases or $50 \%$ ) was in the second decade. Sixty seven patients $(85.9 \%)$ were under the age of 20 . There were 46 male and 32 female patients, a sex ratio of 1.4 to 1 . Sixty six patients $(85 \%)$ had sickle cell anaemia (SS), $11(14 \%)$ sickle cell haemoglobin C (SC), and one had sickle cell thalassaemia.

KNOWN SITES OF BONE INFECTION The total known sites of bone infection were 184 .
The tibia was the commonest site of involvement. Thirty three patients ( 29 with SS and four with SC) or $42 \%$ had multifocal osteomyelitis. Bilateral symmetrical involvement of the limb bones occurred $\rightleftharpoons$ in nine individuals with SS (Fig. 1), and multiple bones of one side were affected in five cases with SS. Asymmetrical multifocal involvement occurred in nine patients (eight with SS and one with SC). Osteomyelitis of long bones most commonly affected the entire diaphyses, but other sites were not immune. The lower limb was affected almost twice as commonly as the upper limb bones.

\section{CLIN I CAL FEATURES}

Most patients had no recognisable predisposing factors; only 16 patients had antecedent infection elsewhere and three others had recent injury. The majority presented late with gross, florid local disease and systemic disturbance (Figs 2 and 3 ).

Fifty two patients $(66 \cdot 7 \%)$ also had associated underlying disorders like septic arthritis (25 patients), severe anaemia with packed cell volume (pcv) less than $20 \%$ (18 patients), jaundice (seven patients), pneumonia (seven patients), heart failure (three patients), marasmus (three cases), and septic pericarditis (one case).

RADIOLOGICAL APPEARANCE

In 23 patients $(29 \%)$ initial $x$ rays showed no bone lesion, but subsequent $x$ rays showed obvious bone 
changes. Osteolysis and periosteal new bone formation were the commonest bone lesions. Other radiological features included pathological fracture, osteoporosis, and a combination of osteolysis and osteosclerosis.
BACTERIOLOGICAL FINDINGS

Thirty six organisms were cultured from 32 patients (Table 1). Salmonella accounted for $50 \%$ of the isolates and gram negative infections for $80 \cdot 6 \%$. All but two isolates of Salmonella were sensitive to

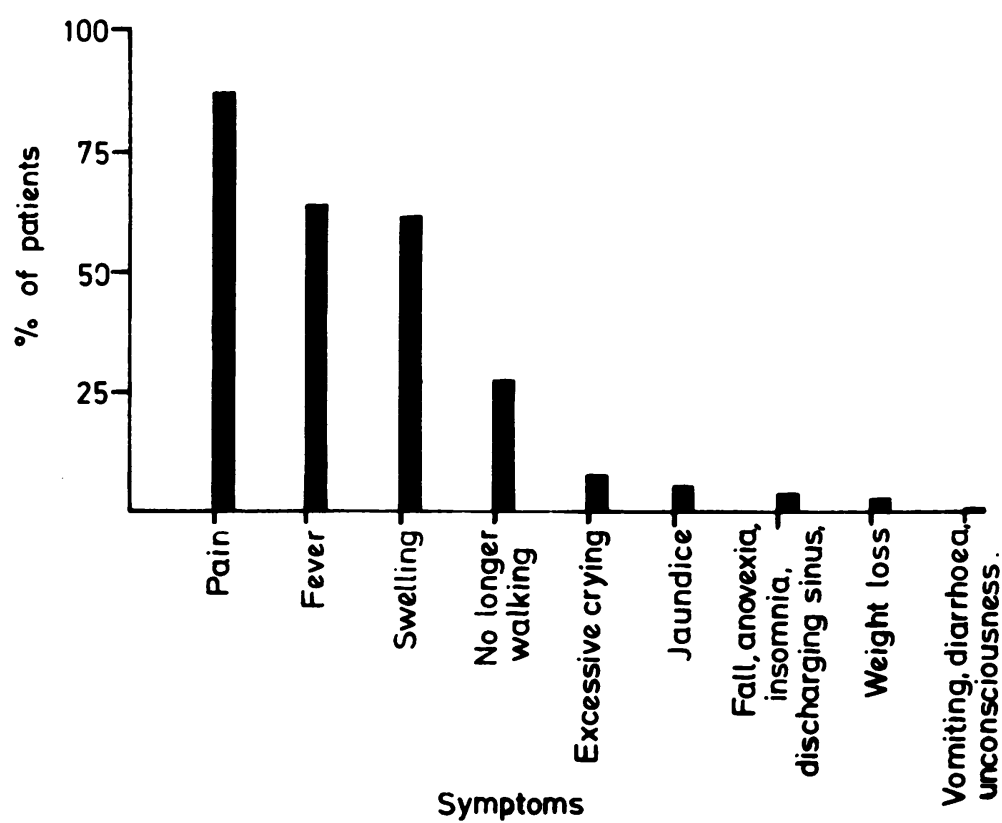

Fig. 2 Symptoms in 78 patients with acute osteomyelitis.

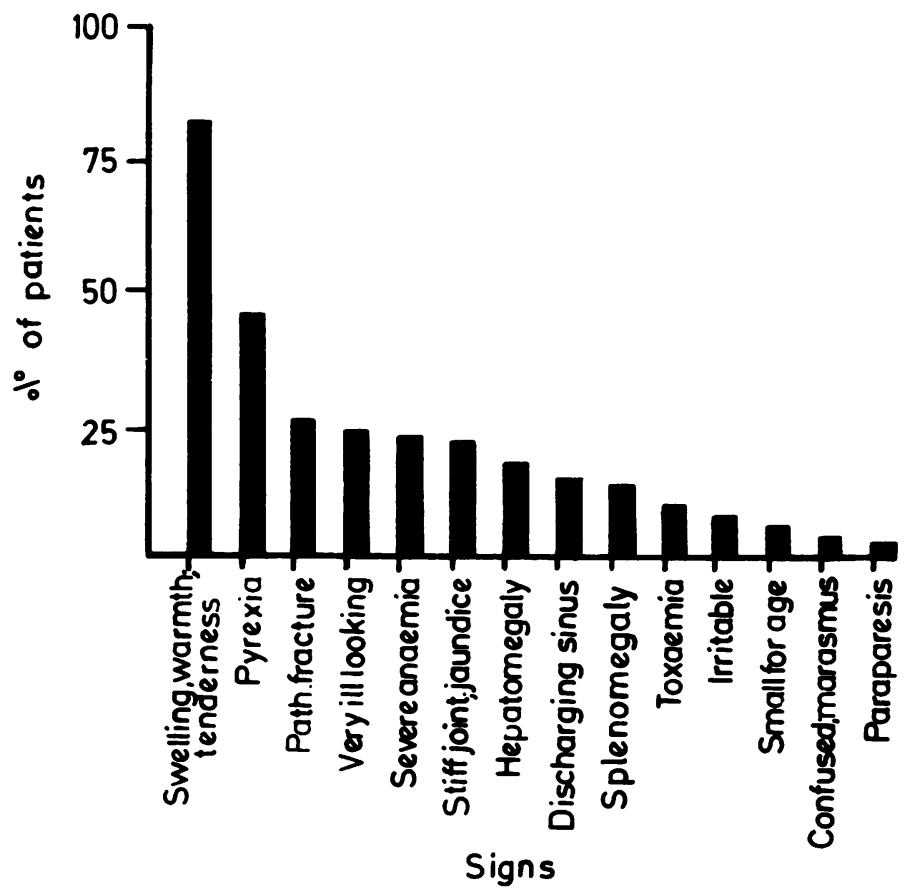

Fig. 3 Clinical signs in patients with acute osteomyelitis. 
Table 1 Source of organisms cultured from 32 patients

\begin{tabular}{|c|c|c|c|c|c|}
\hline \multirow[t]{2}{*}{ Organism } & \multicolumn{3}{|l|}{ Source } & \multirow[t]{2}{*}{ Total } & \multirow[t]{2}{*}{ Percentage of total } \\
\hline & Blood culture & Pus culture & Blood + pus culture & & \\
\hline Salmonella & 4 & 11 & 3 & 18 & $50 \cdot 0$ \\
\hline Staphylococcus aureus & 2 & 4 & & 6 & $16 \cdot 7$ \\
\hline Escherichia coli & & 3 & & 3 & $8 \cdot 3$ \\
\hline Pseudomonas & & 3 & & 3 & $8 \cdot 3$ \\
\hline Klebsiella & 1 & & 1 & 2 & $5 \cdot 6$ \\
\hline Proteus & & 2 & & 2 & $5 \cdot 6$ \\
\hline Anaerobic streptococcus & & 1 & & 1 & $2 \cdot 8$ \\
\hline Citrobacter & 1 & & & 1 & $2 \cdot 8$ \\
\hline Total & 8 & 24 & 4 & 36 & $100 \cdot 0$ \\
\hline
\end{tabular}

chloramphenicol and all but one were sensitive to ampicillin. Twenty six $(72 \%)$ of the organisms isolated showed in vitro sensitivity to a combination of chloramphenicol and cloxacillin.

OTHER LABORATORY RESULTS

The white cell count (WBC) ranged from 4050 to $124000 / \mathrm{mm}^{3}\left(4.05-124 \times 10^{9} / \mathrm{l}\right)$ (mean $17270 / \mathrm{mm}^{3}$ $\left.\left(17 \cdot 27 \times 10^{9} / 1\right)\right)$. In 49 patients $(62 \cdot 8 \%)$ the WBC was over $11000 / \mathrm{mm}^{3}\left(11 \times 10^{9} / \mathrm{l}\right)$, while in $34(43.6 \%)$ it was greater than $14000 / \mathrm{mm}^{3}\left(14 \times 10^{9} / \mathrm{l}\right)$.

The pcv ranged from $5 \%$ to $39 \%$ (mean $23 \%$ ). Patients with SS had a significantly lower pcv (mean $22 \%$; range 5-36\%) than those with SC (mean $29 \%$; range $13-39 \%)(p<0.001)$. Six patients with SS had pcv values between $5 \%$ and $14 \%$ (mean $10 \%$ ).

\section{T R E A T M E N T}

Initial treatment of critically ill patients comprised correction of dehydration and acidosis, intravenous chloramphenicol and cloxacillin, and packed red cell transfusion and diuretic therapy for those with severe anaemia. Heart failure was treated with digitalis. When the patient was stable the antibiotic, reviewed as necessary, was given orally. Owing to shortage of hospital beds, the less acutely ill patients were treated as outpatients. The duration of antibiotic therapy varied widely but usually lasted for between 12 and 15 weeks. Splintage was an essential adjunct to treatment. Antimalarial therapy and folic acid were used routinely, and analgesics and antipyretic drugs were given as necessary.

Thirty eight patients $(48.7 \%)$ also had some form of operative treatment. Incision and drainage of abscess was performed in 35 bones ( 30 SS and five SC) of 30 patients (27 with SS and three with SC) and needle aspiration in 11 bones (10 SS and one SC) of eight patients (seven with SS and one with $\mathrm{SC}$ ).

\section{SEQUELA}

There were no deaths, but the incidence and severity of complications were high. In 35 patients $(45 \%)$ control of infection was achieved without any complication for a minimum of six months. The $Z$ complications which occurred in the other 43 patients included chronicity (in 20 bones of 17 patients), pathological fracture (in 22 bones of 17 patients), joint stiffness (in eight patients), and septic necrosis of the upper femoral epiphysis in sion patients. Factors that appeared to be associated wit chronicity were late presentation at three or mora weeks of onset of symptoms; affection of the tibia, femur, or humerus; evacuation of abscess by incision and drainage (in nine patients), and patients aged 10 or more years.

\section{Discussion}

The pattern and complications of acute osteomyelitis in sickle cell disease in the present series were similar in many respects to previous reports from West Africa, ${ }^{2459}$ but differed in important aspects from reports from non-malarial countries. ${ }^{1}{ }^{10-12}$

As in previous studies acute osteomyelitis was predominantly a disease of children. ${ }^{1412}$ The bone most commonly involved was the tibia. In some series, however, the humerus or the femur was the most commonly affected bone. ${ }^{313}$ As in previous reports acute osteomyelitis of long bones was often located in the diaphyses rather than in the of metaphyses, ${ }^{14}$ even in children, though in an $N$ appreciable number the epiphyses were involved, N and there was associated septic arthritis in 25 instances. The prognosis is worse with involvement of epiphyses and joints than with diaphyseal osteomyelitis. $^{13}$

Salmonella, the commonest infective organism in the series, accounted for $50 \%$ of the positive 
cultures. This is consistent with most previous studies from tropical Africa ${ }^{39}$ and elsewhere. ${ }^{11215}$ The incidence of Staph aureus osteomyelitis in our series was $16.7 \%$, which is comparable with earlier reports from East Africa. ${ }^{3}$ In contrast, the reported incidence of staphylococcal osteomyelitis in patients without sickle cell disease in Africa ${ }^{2}$ and elsewhere ${ }^{10}$ is over $50 \%$. This peculiar association of salmonella osteomyelitis and SS was first reported in $1925,{ }^{16}$ first recognised in $1951,{ }^{17}{ }^{18}$ and has been amply confirmed by others. ${ }^{2} 3515$

From the sensitivity results a combination of chloramphenicol and cloxacillin would be effective against $72 \%$ of the organisms isolated. We therefore propose this combination as the 'best guess' antibiotic for acute osteomyelitis in patients with sickle cell disease in West Africa, rather than only chloramphenicol or ampicillin commonly used elsewhere. ${ }^{13}$ We have found this combination to be quite effective in practice. A combination of gentamycin and cloxacillin, which we had earlier suggested should be used in critically ill patients with multifocal skeletal infection, ${ }^{19}$ was later found not to be very effective in practice.

The best results as regards control of infection were obtained in the eight patients who were treated by needle aspiration and antibiotics, while the worst results occurred in those treated by open drainage of abscess plus systemic antibiotics. None of the former but nine of the latter patients developed chronicity. Thus needle aspiration should, whenever possible, be the preferred method of evacuating any collection of pus in these patients.

Supported in part by a grant awarded by the University of Ibadan Senate.

\section{References}

1 Engh C A, Hughes J L, Abrams R C, Bowerman J W.
Osteomyelitis in the patient with sickle-cell disease, diagnosis and management. J Bone Joint Surg 1971; 53A: 1-15.

2 Ebong W W, Oyemade G A A. Acute haematogenous osteomyelitis in Nigeria. Trop Geogr Med 1978; 30: 451-61.

3 Huckstep R L. The management of osteomyelitis in East Africa. East Afr Med J 1968; 45: 429-62.

4 Adeyokunnu A A, Hendrickse R G. Salmonella osteomyelitis in childhood. A report of 63 cases seen in Nigerian children of whom 57 had sickle cell anaemia. Arch Dis Child 1980; 55: 175-84.

5 Hendrickse R G, Collard P. Salmonella osteitis in Nigerian children. Lancet 1960; i: 80-2.

6 Ebong W W. Acute osteomyelitis three years after a closed fracture in an adult with sickle-cell anaemia. J Bone Joint Surg 1980; 62A: $1196-8$.

7 Ebong W W. Bilateral pelvic osteomyelitis in children with sickle-cell anaemia. Report of four cases. J Bone Joint Surg 1982; 64A: 945-7.

8 Huckstep R L. Treatment of acute osteomyelitis in sickle cell anaemia. J Bone Joint Surg 1967; 49B: 594.

9 Sennara H, Gorry F. Orthopedic aspects of sickle cell anaemia and allied hemoglobinopathies. Clin Orthop 1978; 130: 154-7.

10 Mollan R A B, Piggot J. Acute osteomyelitis in children.J Bone Joint Surg 1977; 59B: 2-7.

11 Ortiz-Neu C, Marr J S, Cherubin C E, Neu H C. Bone and joint infections due to salmonella. J Infect Dis 1978; 138: 820-8.

12 Robinson M G. Clinical aspects of sickle cell disease. In: Levere P D, ed. Sickle cell anemia and other hemoglobinopathies. New York: Academic Press, 1975; 87-112.

13 Specht E E. Hemoglobinopathic salmonella osteomyelitis. Orthopedic aspects. Clin Orthop 1971; 79: 110-8.

14 Lagundoye S B. Radiological features of sickle cell anaemia and related haemoglobinopathies in Nigeria. Afr J Med Sci 1970; 1: 315-42.

15 Barrett-Connor E. Bacterial infection and sickle cell anemia. An analysis of 250 infections in 166 patients and a review of the literature. Medicine (Baltimore) 1971; 50:97-112.

16 Carrington G L, Davidson W C. Multiple osteomyelitis due to bacillus paratyphosus B. Demonstration of bacillus in fresh blood preparation. John Hopkins Med J 1925; 36: 428-30.

17 Hodges F T, Holt J F. Year book of radiology, 1950-1951. Chicago: Year Book Publishers, 1951: 89.

18 Lambotte-Legrand $\mathrm{J}$ A, Lambotte-Legrand $\mathrm{C}$. L'anémie à hématies falciformes chez l'enfant indigene du Bas-Congo. Memoires de l'Institut Royal Colonial Belge, Section des Sciences Naturelles Medicales 1951; 19: 23.

19 Ebong W W. The treatment of severely ill patients with sickle cell anaemia and associated septic arthritis. Clin Orthop 1980; 149: $145-52$. 